\title{
Türkiye Ekonomisinde 2002 - 2016 Dönemindeki Mali Çarpanın Kova Yaklaşımı ile İncelenmesi
}

\author{
Fiscal Multiplier in Turkish Economy (2002 - 2016 Period): Bucket Approach \\ İbrahim TOKATLIOĞLU ${ }^{1}$, Nagihan Demet YAVUZ BAHADIR \\ Article Info \\ Article History: \\ Date Submitted: 24.05.2019 \\ Date Accepted: 03.08.2019 \\ Jel Classification \\ E62,H1O, H5O \\ Keywords: \\ Turkish Economy, \\ Abstract \\ Recent researches emphasize that the effect of fiscal expansion on the output level \\ varies according to countries and economic conjuncture. Researchers often use \\ model-based approaches or statistical methods based on variance analysis to \\ predict fiscal multiplier. In this study, the size of the fiscal multiplier in the \\ Turkish economy is predicted via an alternative approach called "Bucket \\ Approach". The findings obtained for the 2002-2016 period, have similarities \\ with other studies conducted for Turkish economy.
}

Fiscal Multiplier,

Bucket Approach

\section{Özet}

Son dönemlerde ekonomi literatüründe mali genişlemelerin çıktı düzeyinde yarattığı etkinin ülkelere ve ekonomik konjentüre göre değişiklik gösterdiği konusu üzerinde sıklıkla durulmaktadır. Araştırmacılar, mali çarpanı tahmin etmeye çalışırken model tabanlı yaklaşımları veya varyans analizine dayalı istatistiksel metotları sıklıkla kullanmaktadır. $\mathrm{Bu}$ çalışmada, mevcut metotlara alternatif olarak sunulan Kova Yaklaşımı kullanılarak 2002-2016 yıllarında Türkiye ekonomisindeki mali çarpanın büyüklüğü ölçülmüştür. Çalışma sonucunda elde edilen bulguların Türkiye için yapılan diğer çalışmalarla benzerlik taşıdığı görülmektedir.

\section{Giriş}

1930'larda sanayileşmiş batılı devletlerarasında hızla yayılan 20. yüzyılın en büyük ekonomik buhranı, Adam Smith'in başlattığı Klasik İktisadi Ekolü temelinden sarsmıştır. John Maynard Keynes (1936), Adam Smith'in bahsettiği dengenin uzun dönemli olduğunu vurgulayarak kısa vadede piyasayı dengede tutmak için devlet müdahalesinin zorunlu olduğunu

\footnotetext{
${ }^{1}$ Prof. Dr. Ankara Hacı Bayram Veli Üniversitesi, iliBF, İktisat Bölümü
} 
savunmuştur. Keynes'in fikirleri uzun bir süre boyunca ekonomi çevreleri tarafindan destek görmüş ve 1980'li yıllara kadar varlığını farklı yaklaşımlar altında sürdürmüştür. 1980'li yıllarda liberal fikirler tekrar egemen olmuş ve büyük teknolojik ilerlemelerin yaşandığı yeni bir küreselleşme dalgası başlamıştır. Bu dalga, 2007 - 2008 yıllarında Amerika Birleşik Devletleri'nde ortaya çıkan, akabinde birçok gelişmiş ve gelişmekte olan ülkeye sirayet eden morgage krizine kadar devam etmiştir. (McDonough, 2008) Mortgage krizi ile birlikte aynı 1930'lardaki büyük buhran döneminde olduğu gibi piyasalarda devlet müdahalesinin gerekliliği tekrar sorgulanmaya başlanmıştır. Birçok ülke liberal politikalardan uzaklaşarak, piyasadaki talebi canlı tutmaya gayret etmiş ve ivedi mali paketler hazırlayarak harcamalarını arttırmıştır. Ancak modern çağda ekonomideki durgunluğun önlenmesi ve işsizliğin azaltılması için devlet harcamalarının arttırılması fikri hala iyi bir çözüm olarak düşünülse de, 1930'larda olduğu gibi basit bir metot olarak algılandığını iddia etmek hatalı olacaktır. (Auerbach ve Gorodnichenko, 2012)

\subsection{Maliye Politikasına Yönelik Yaklaşımlar}

Maliye politikalarına ve mali çarpana yönelik yaklaşımlar son dönemlerde özellikle de 2008 mortgage krizi sonrasında oldukça farklılaşmıştır. 1980'lere kadar olan çalışmalarda üzerinde durulan konu, maliye politikalarının piyasada yaratacağı etkinin pozitif mi yoksa negatif mi olacağ1 sorusudur. Keynesyen görüşe göre devlet harcamalarındaki artışın piyasayı canlandırarak toplam çıtıyı arttıracak, neo-klasik görüşe göre ise negatif bir gelir etkisi yaratarak bireylerin harcamalarının devlet harcamalarındaki artış miktarından daha fazla azalması ile sonuçlanacak ve toplam çıktı düzeyinin azalmasına yol açacaktır (Barro, 1989). Literatürde bu durum dışlama etkisi (crowding-out) olarak adlandırılmaktadır. Maliye politikasının etkinliği, iktisat literatüründe 1930'lu yıllardan 1980'li yıllara kadar temel tartışma konusu olmuştur. 1980 sonrasında ise literatürdeki tartışma maliye politikasının mutlak etkinliği veya etkinsizliği üzerine değil mali çarpanın değeri ve bu değerin zamana ve mekana göre değişkenliği üzerine odaklanmıştır. 2008 mortgage krizi ile tartışma daha da derinleşmiş ve son dönemlerde ekonomi literatüründe en çok araştırılan konulardan biri haline gelmiştir.

Birçok ekonomist krizden çıkış yolu olarak devlet harcamalarının arttırılması yönündeki reçetenin her ülkeye doğrudan uygulanamayacağı hususunda hemfikirdir. (Blanchard ve Leigh, 2013) Ülkelerin ekonomilerinin birbirinden farklı dinamikler üzerine kurulu olduğu dikkate alındığında mali çarpanın, her ekonomide aynı oranda pozitif bir etkisi olduğunu varsaymak 
mümkün değildir. (Corsetti, Meier ve Muller, 2012). Ilzetzki, Mendoza ve Vegh (2011) 44 ülkeden oluşan veri seti ile yaptıkları ampirik analizde mali çarpanın ülkelere göre faklılaştığını göstermiştir. Roberto Perotti tarafından 2004 yılında yapılan araştırmada vektör otoregresif model aracılığıyla 5 OECD ülkesinde maliye politikasının GSYİH, enflasyon ve faiz üzerindeki etkisi incelenmiştir. Anja Baum, Marcos Poplawski-Ribeiro ve Anke Weber tarafindan 2012'de İtalya haricindeki G7 ekonomileri için ülke bazında mali çarpan ve ekonomik konjentür arasındaki ilişki araştırılmıştır. Tüm bu çalışmalarda mali çarpanın farklı ülkelerde farlı değerler aldığı ispatlanmaktadır.

Bununla birlikte mali çarpanın sadece farklı ülkelerde değil aynı ekonomi içerisinde dahi farklı ölçülebildiği son dönemdeki akademik çalışmalarda ispatlanmaktadır. Auerbach ve Gorodnichenko (2012) yaptıkları ampirik çalışmada Amerikan ekonomisinde mali çarpanın durgunluk dönemlerinde daha yüksek bir değer aldığını Yumuşak Geçişli Vektör Otoregresif (STVAR - Smooth Transition Vector Autoregression) Modeli kullanarak ortaya koymuştur. Hernandez de Cos ve Moral-Benito (2013) İspanya için mali çarpanı VAR analizi kriz dönemlerinde 4; normal zamanlarda ise 0.6 olarak tahmin etmiştir. Benzer başka bir çalışmada, Robert E. Hall (2009) ABD'de II. Dünya Savaşı ve Kore Savaşı sırasında mali çarpanı vektör otoregresif modeller aracılığıyla 0.7 ila 1.0 aralığında tahmin etmiştir.

Görüleceği üzere, güncel literatür mali çarpanın mekana ve zamana göre farklılık göstereceğini kanıtlama gayreti içindedir. Bu doğrultuda mali çarpanın değerini bilmeden ülkeler için kamu harcamalarına dayalı krizden çıkış reçeteleri uygulamak; halihazırda kırılgan olan ekonomilerin daha da çıkmaza girmesiyle sonuçlanabilir. Dolayısıyla mali çarpanın değerinin belirlenmesi ekonomi yönetimi açısından son derece önemlidir. Bununla birlikte, mali çarpanı hesaplamak oldukça zor ve karmaşık bir işlemdir.

\subsection{Mali Çarpanın Hesaplanması}

Güncel akademik çalışmalarda, mali çarpanın değeri tahmin edilmeye çalışılırken model tabanlı yaklaşımların veya varyans analizine dayalı istatistiksel metotların kullanıldığı görülmektedir. Özellikle Neo Keynesyen modellerde sıklıkla Dinamik Stokastik Genel Denge (DSGE - Dynamic Stochastic General Equilibrium Models) analizi kullanıldığı gözlenmektedir. Bu yöntem, ekonomi teorisinin kurumsal çerçevesine yakın olduğundan ve saf istatistiksel analizlerde ortaya çıkan yorumlama güçlüklerinden uzak durulmasını 
sağladığından bir çok araştırmacı tarafından tercih edilmektedir. Araştırmacılar, Dinamik Stokastik Genel Denge modellerinde reel ekonomiye dayalı varsayımlar kullanıldığından bulguların yorumlanmasında oldukça güçlü sonuçlar ortaya çıktığını vurgulamaktadırlar. (Ganelli ve Tervala, 2016) Bununla birlikte, Mortgage krizi öncesinde maliye politikalarının toplam çıktı üzerindeki etkisini inceleyen çalışmaların birçoğunda doğrusal (linear) VAR modelleri kullanıldığı gözlemlenmektedir. Vektör otoregresyon (VAR) modelleri çoklu zaman serileri arasındaki ilişkiyi ve karşılıklı bağımlılığı ekonometrik olarak analiz etmektedir. Bir vektör otoregresyon modelinde yer alan tüm değişkenler, modeldeki değişkenin kendi gecikmeleri ve diğer tüm değişkenlerin gecikmelerine bağlıdır. Vektör otoregresyon analizinin teoriden bağımsız olması sebebiyle yapısal modellerin tanımlama kısıtlarının yol açtığı zorlukları bertaraf ettiği düşünülmektedir. Mali çarpanla ilgili yapılan araştırmalarda Doğrusal VAR, Threshold VAR (TVAR) ve Yumuşak Geçişli VAR (STVAR - Smooth Transition Vector Autoregression) analizlerine sıklıkla başvurulmaktadır.

Birçok avantajları bulunmasına rağmen Dinamik Stokastik Genel Denge ve Vektör Otoregresyon Modelleri oldukça detaylı analizlere dayanan zorlu yöntemlerdir. Dinamik Stokastik Genel Denge Modellerinde tanımlama ve varsayımsal zorluluklar yaşanırken, Vektör Ootoregresyon (VAR) Modellerde ise istatistiki verilerin yetersizliği sorun oluşturabilmektedir. Bu metotlarda araştırma yapabilmek için ekonomi literatürünün kurumsal çerçevesine hakim olmak ayrıca istatistiki verilerin mevcut ve sağlıklı olması gerekli koşullardır. Ancak her ekonomide istatistiki verilerin kapsamlı olduğunu söylemek mümkün değildir. Özellikle az gelişmiş ve gelişmekte olan ülkelerde bu makroekonomik göstergelerin ne kadar kapsamlı olduğu tartışmalı bir husustur. Bu sebeple Uluslararası Para Fonu (IMF) 2014 yılında Kova Yaklaşımı'nı (Bucket Approach) ortaya atarak az gelişmiş ve gelişmekte olan ülkelerde son derece basit bir şekilde mali çarpanın hesaplanmasını sağlamaya çalışmıştır. (Batini, Eyraud ve Weber, 2014)

Bu çalışmada, Kova Yaklaşımı kullanılarak 2002-2016 yıllarında Türkiye ekonomisindeki mali çarpanın büyüklüğü ölçülecek ve bulgular farklı yöntemler kullanan araştırmaların sonuçları ile kıyaslanacaktır. Kova yaklaşımın tercih edilmiş olmasının sebebi hem kolay bir metot olması hem de daha önce Türkiye için bu yaklaşımı kullanarak bir çalışmanın yapılmamış olmasidir. 


\section{Kova Yaklaşımı}

Son dönemlerdeki bilimsel çalışmaların gösterdiği üzere mali çarpan zamana ve ülkeye göre farklılıklar göstermektedir. $\mathrm{Bu}$ nedenle, evrensel çarpanların sistematik kullanımından kaçınılması ve bunun yerine, her ülke ve dönem özelinde incelenen ve tespit edilen mali çarpan değerleri baz alınarak politikaların belirlenmesi gerekmektedir. Bununla birlikte istatistiki verilerin yetersizliği ve tanımlama zorlukları gibi nedenlerle mevcut bilimsel yöntemlerle mali çarpanı hesaplamak özellikle az gelişmiş ve gelişmekte olan ülkeler için oldukça güç bir süreçtir. Nicoletta Batini, Luc Eyraud, ve Anke Weber (2014) yılında yayınlanan çalışmalarında, bu sorun için "Kova Yaklaşımı" adıyla basit bir çözüm önermektedir. Araştırmacılar, Kova Yaklaşımını üretirken mali çarpanın değerinin ülkelerin karakteristik ve konjenktürel özelliklerine göre değiştiğini ortaya koyan diğer bilimsel çalışmalardan esinlenmişlerdir.

Bu kapsamda hesaplama üç ana adımda tamamlanmaktadır. Birinci adımda ülkelerin belli başlı karakteristik özellikleri verilen ölçütler altında incelenmekte ve varlıklarının tespiti halinde her özellik için ülkeye bir puan atanmaktadır. Sonraki adımda ülkeler, karakter özelliklerine göre aldıkları toplam puanlar dikkate alınarak kovalara / gruplara ayrılmaktadır. Bu aşamada her grup için normal dönem çarpan değeri atanmaktadır. Üçüncü ve son adımda ise ülke için atanan normal dönem çarpan değerleri ülkenin içinde bulunduğu konjenktürel duruma (iş döngüsü ve para politikası duruşu) göre ölçeklendirilmektedir. Bu sayede büyüme ve kriz dönemlerinde mali çarpanın alacağı değerlerin farklılığ 1 ortaya koyulmaktadır.

\subsection{Kova Yaklaşımının Birinci Adımı: Göstergelerin Ölçülmesi}

İlk adımda ülkelere ekonomilerinin bazı karakteristik özellerine göre puan verilmektedir. $\mathrm{Bu}$ özellikler Ticaret Serbestliği, İşgücü Piyasası Katılı̆̆ı, Otomatik Dengeleyicilerin Büyüklüğü, Döviz Kuru Rejiminin Serbestliği, Kamu Borç Stoğunun Büyüklüğü ve Kamu Mali Yönetimin Verimliliğidir. Nicoletta Batini, Luc Eyraud, ve Anke Weber (2014) çalışmalarında her bir karakteristik için ölçütler sunmaktadır. Bu aşamada söz konusu ölçütler dikkate alınarak, Türkiye ekonomisinin 2002-2006 dönemindeki karakteristiği incelenecektir. 


\subsubsection{Ticaret Serbestliği}

İthalat eğilimi daha düşük olan ülkeler (yani, yalnızca kısmen ticarete açık olan ülkeler) daha yüksek mali çarpanlara sahip olma eğilimindedir, çünkü ithalat yoluyla yapılan talep kaçağı daha az belirgindir. (Barrell ve diğerleri, 2012; Ilzetzki ve diğerleri, 2013) Nicoletta Batini, Luc Eyraud, ve Anke Weber (2014) çalışmalarında İthalatın iç talebe oranı yüzde 30'un altında olan ekonomilerin ticaret serbestliğinin düşük olduğunu belirtmektedir. Yaklaşıma göre, ticaret serbestliğinin düşük olması durumunda ülkeye bir puan atanması beklenmektedir. Türkiye İstatistik Kurumu'nun (TÜİK) Türkiye'nin 2002-2006 y1lları arasında harcama yöntemi ile hesaplanan gayrisafi yurtiçi hasıla istatistiği dikkate alınarak, aşağıdaki tablo oluşturulmuştur. Yurtiçi talep devletin nihai tüketim harcamaları, yerleşik hane halkı ve hane halkına hizmet eden kar amacı olmayan kuruluşların nihai tüketim harcaması, gayrisafi sabit sermaye oluşumu ve stok değişmeleri sütunlarının toplamına eşittir.

Tablo 1. Harcama Yöntemiyle Gayrisafi Yurtiçi Hasıla (Cari Fiyatlarla)

\begin{tabular}{|c|c|c|c|c|c|c|}
\hline & Gayrisafi & $\begin{array}{c}\text { Devletin nihai } \\
\text { türtiçi hasıla } \\
\text { (Bin TL) } \\
\text { harcamaları } \\
\text { (Bin TL) } \\
\text { ve hanehalkılna } \\
\text { hizmet eden kar } \\
\text { amacı olmayan } \\
\text { kuruluşların nihai } \\
\text { tüketim harcamasi } \\
\text { (Bin TL) }\end{array}$ & $\begin{array}{c}\text { Gayrisafi sabit } \\
\text { sermaye } \\
\text { oluşumu } \\
\text { (Bin TL) }\end{array}$ & $\begin{array}{c}\text { Stok } \\
\text { değişmeleri } \\
\text { (Bin TL) }\end{array}$ & $\begin{array}{c}\text { Yurtiçi Talep } \\
\text { (Bin TL) }\end{array}$ \\
\hline 2002 & 359358871 & 46479185 & 231290817 & 70474243 & 5864931 & 354109176 \\
\hline 2003 & 468015146 & 59448404 & 308606620 & 97573332 & 7606120 & 473234476 \\
\hline 2004 & 577023497 & 71779491 & 374914073 & 146656800 & -1216233 & 592134131 \\
\hline 2005 & 673702943 & 82898243 & 431595428 & 179547342 & 2578464 & 696619477 \\
\hline 2006 & 789227555 & 102712569 & 491457673 & 226412643 & 6924358 & 827507244 \\
\hline 2007 & 880460879 & 118862212 & 551480230 & 247402873 & 5410313 & 923155628 \\
\hline 2008 & 994782858 & 136337707 & 612911888 & 267077456 & 20771958 & 1037099009 \\
\hline 2009 & 999191848 & 157576388 & 619462058 & 223566234 & 6432113 & 1007036794 \\
\hline 2010 & 1160013978 & 173684929 & 731460489 & 288473760 & 24414075 & 1218033253 \\
\hline 2011 & 1394477166 & 191075146 & 880851522 & 391383400 & 44651396 & 1507961463 \\
\hline 2012 & 1569672115 & 223401702 & 979068044 & 428831788 & 15450556 & 1646752091 \\
\hline 2013 & 1809713087 & 255615056 & 1120356921 & 516209715 & 22599973 & 1914781666 \\
\hline 2014 & 2044465876 & 288096259 & 1242228534 & 590742457 & 2835013 & 2123902263 \\
\hline 2015 & 2338647494 & 324551507 & 1411800255 & 694786860 & -31499083 & 2399639539 \\
\hline 2016 & 2608525749 & 386976636 & 1560518475 & 764661719 & -28362562 & 2683794268 \\
\hline
\end{tabular}

Kaynak: Türkiye İstatistik Kurumu 
Tablo 2. İthalat / Yurtiçi Talep Oranı

\begin{tabular}{|l|c|c|c|}
\hline & $\begin{array}{c}\text { Mal ve hizmet ithalatı } \\
\text { (Bin TL) }\end{array}$ & $\begin{array}{c}\text { Yurtiçi talep } \\
\text { (Bin TL) }\end{array}$ & $\begin{array}{c}\text { İthalat / Yurtiçi } \\
\text { Talep Oranı }\end{array}$ \\
\hline 2002 & 51553797 & 354109176 & 0.15 \\
\hline 2003 & 69339692 & 473234476 & 0.15 \\
\hline 2004 & 97539766 & 592134131 & 0.16 \\
\hline 2005 & 116774151 & 696619477 & 0.17 \\
\hline 2006 & 139576174 & 827507244 & 0.17 \\
\hline 2007 & 170062715 & 923155628 & 0.18 \\
\hline 2008 & 201963574 & 1037099009 & 0.19 \\
\hline 2009 & 140928421 & 1007036794 & 0.14 \\
\hline 2010 & 185544332 & 1218033253 & 0.15 \\
\hline 2011 & 240841676 & 1507961463 & 0.16 \\
\hline 2012 & 236545141 & 1646752091 & 0.14 \\
\hline 2013 & 251661250 & 1914781666 & 0.13 \\
\hline 2014 & 242177117 & 2123902263 & 0.11 \\
\hline 2015 & 207234359 & 2399639539 & 0.09 \\
\hline 2016 & 198618235 & 2683794268 & 0.07 \\
\hline Ortalama & $\mathbf{1 7 0 0 2 4 0 2 7}$ & $\mathbf{1 2 9 3 7 1 7 3 6 5}$ & $\mathbf{0 . 1 3}$ \\
\hline
\end{tabular}

Kaynak: Türkiye İstatistik Kurumu

Tablo 2'de görüldüğü üzere, Türkiye ekonomisinde 2002-2016 y1lları arasında yıllık bazda veya ortalamada toplam ithalat tutarının, yurtiçi talebe oranı eşik olan değerlendirilen \%30 rakamının çok altındadır. $\mathrm{Bu}$ sebeple ticaret serbestliği karakterine 1 puan atanmas 1 gerekmektedir.

\subsection{1. İşgücü Piyasası}

Kova yaklaşımında incelenen ikinci özellik işgücü piyasasının esnekliğidir. Araştırmacılara göre daha katı işgücü piyasasına sahip olan ülkelerde, ücretlerdeki esneklik de düşük olacağ 1 için üretimin talep şoklarına vereceği cevap artış eğilimindedir. (Cole ve Ohanian, 2004) İşgücü piyasasının katılığını anlayabilmek için ülkedeki işçi sendikalarının gücüne ve işgücü piyasasının hukuki olarak düzenlenmiş olup olmadığına bakılmalıdır. Araştırmacılara göre işgücü piyasasına yönelik endeksler aracılı̆̆ıyla bu kriter hakkında yorum yapılabilir. Milan Deskar-Škrbić ve Hrvoje Šimović tarafindan (2015) yapılan araştırmada, Hırvatistan, Sırbitan ve Slovenya için Kova Yaklaşımı kullanılarak mali çarpan tahmin edilmeye çalışılmıştır. Araştırmacılar bu makalede söz konusu ülkelerdeki işgücü piyasasının esnekliğini, Dünya 
Bankasının yayınladığı "İşgücü Piyasası Etkinliğgi" endeksi ile ölçmüşlerdir. Yazarlara göre endekste 4'ün altında yer alan ülkelerde işgücü piyasası katıdır. İlgili çalışma referans alınarak, Türkiye için ilgili endeksin sonuçları aşağıdaki tabloda sunulmuştur.

Tablo 3. Dünya Bankasının İşü̈cü Piyasası Etkinliği Endeksi

\begin{tabular}{|c|c|}
\hline & Dünya Bankası İşgücü Piyasası Etkinliği Endeksi \\
\hline 2002 & 3.58 \\
\hline 2003 & 3.58 \\
\hline 2004 & 3.58 \\
\hline 2005 & 3.58 \\
\hline 2006 & 3.58 \\
\hline 2007 & 3.60 \\
\hline 2008 & 3.57 \\
\hline 2009 & 3.65 \\
\hline 2010 & 3.57 \\
\hline 2011 & 3.51 \\
\hline 2012 & 3.79 \\
\hline 2013 & 3.74 \\
\hline 2014 & 3.48 \\
\hline 2015 & 3.46 \\
\hline 2016 & 3.39 \\
\hline Ortalama & $\mathbf{3 . 5 8}$ \\
\hline
\end{tabular}

Kaynak: Dünya Bankas1

Dünya Bankası tarafından yayınlanan endekste, 2002-2006 yıllarında Türkiye'nin skoru yer almamaktadır. Bununla birlikte diğer yıllar incelendiğinde endekste büyük ölçekte değişiklikler olmadığ1 görülmektedir. Bu sebeple ilgili yıllar için alınacak değer, ortalama olarak kabul edilmiştir. Görüleceği üzere, yıllar bazında da ortalamada da Türkiye'nin endeks puanı 4'ün altındadır. Dolayısıyla işgücü piyasası katılığı kriterine 1 puan atanması gerekmektedir.

\subsubsection{Otomatik Dengeleyiciler}

Diğer bir karakteristik özellik ise otomatik dengeleyicilerin büyüklüğüdür. Araştırmalara göre daha büyük otomatik stabilizatörler mali çarpanları azaltır, çünkü mekanik olarak transferlerin ve vergilerin otomatik tepkisi başlangıçtaki mali şokun bir kısmını dengeler, böylece GSYİH üzerindeki etkisini azaltır. (Dolls, Fuest, ve Peichl, 2012) Nicoletta Batini, Luc Eyraud, ve Anke Weber'e göre (2014) otomatik dengeleyiciler, kamu harcamalarının nominal GSYİH'ye oranı 
ile ölçülebilir ve dengeleyiciler oran 0.40'ın altında olduğunda düşük olarak kabul edilmelidir. Türkiye İstatistik Kurumu'ndan (TÜİK) alınan Türkiye'nin 2002-2006 yılları arasında harcama yöntemi ile hesaplanan gayrisafi yurtiçi hasılası istatistiği kullanılarak aşağıdaki tablo oluşturulmuştur.

Tablo 3. Cari Fiyatlarla GSYİH ve Kamu Harcamaları

\begin{tabular}{|c|c|c|c|}
\hline & $\begin{array}{c}\text { Gayrisafi yurtiçi hasıla } \\
\text { (Bin TL) }\end{array}$ & $\begin{array}{c}\text { Devletin nihai tüketim harcamaları } \\
\text { (Bin TL) }\end{array}$ & $\begin{array}{c}\text { Devlet harcamaları/ } \\
\text { GSYï oranı }\end{array}$ \\
\hline 2002 & 359358871 & 46479185 & 0.13 \\
\hline 2003 & 468015146 & 59448404 & 0.13 \\
\hline 2004 & 577023497 & 71779491 & 0.12 \\
\hline 2005 & 673702943 & 82898243 & 0.12 \\
\hline 2006 & 789227555 & 102712569 & 0.13 \\
\hline 2007 & 880460879 & 118862212 & 0.13 \\
\hline 2008 & 994782858 & 136337707 & 0.14 \\
\hline 2009 & 999191848 & 157576388 & 0.16 \\
\hline 2010 & 1160013978 & 173684929 & 0.15 \\
\hline 2011 & 1394477166 & 191075146 & 0.14 \\
\hline 2012 & 1569672115 & 223401702 & 0.14 \\
\hline 2013 & 1809713087 & 255615056 & 0.14 \\
\hline 2014 & 2044465876 & 288096259 & 0.14 \\
\hline 2015 & 2338647494 & 324551507 & 0.14 \\
\hline 2016 & 2608525749 & 386976636 & 0.15 \\
\hline Ortalama & $\mathbf{1 2 4 4 4 8 5 2 7 1}$ & $\mathbf{1 7 4 6 3 3 0 2 9}$ & $\mathbf{0 . 1 4}$ \\
\hline
\end{tabular}

Kaynak: Türkiye İstatistik Kurumu

Yıllar bazında da ortalamada da Türkiye'nin devlet harcamalarının GSYİH içindeki payı oldukça düşüktür. Bu karakteristik özellikten de Türkiye ekonomisine 1 puan atanması gerekmektedir.

\subsubsection{Döviz Kuru Rejimi}

Araştırmalara göre esnek döviz kuru rejimi olan ülkeler daha küçük çarpanlara sahip olma eğilimindedir, çünkü döviz kuru hareketleri isteğe bağlı maliye politikasının ekonomi üzerindeki etkisini dengeler. (Born, Juessen ve Mueller, 2013) Bu özellikte döviz kuru rejiminin kontrol edilmesi gerekmektedir. Türkiye'de 2001 yılında esnek kur rejimine geçilmiş ve bu rejim günümüze kadar uygulanmıştır. Dolayısıyla bu karakteristikten Türkiye'ye puan verilmeyecektir. 


\subsubsection{Kamu Borç Stoku}

Kova yaklaşımının önem gösterdiği diğer bir yaklaşım ise kamu borç stokudur. Kamu borcu yüksek olan ülkelerde mali çarpanlar daha düşüktür çünkü ek mali genişleme risk priminde artışa neden olabilir ve özel sektör güvenini azaltabilir, böylece tüketimi ve yatırımı negatif etkiler. (Kirchner, Cimadomo ve. Hauptmeier, 2010) Araştırmacılara göre gelişmekte olan ülkeler için kamu borç stokunun GSYİH'ya oranı \%40'ın altındaysa borç stoku düşük kabul edilebilir. Gelişmiş ülkelerde ve az gelişmiş ülkelerde bu oran değişiklik gösterebilir. Hazine ve Maliye Bakanlığının yayınladığı istatistiklerde yıllık olarak bu oran sunulmaktadır.

Tablo 4. Cari Fiyatlarla GSYİH ve Kamu Harcamaları

\begin{tabular}{|c|c|c|c|}
\hline & $\begin{array}{c}\text { Devlet Harcamaları / } \\
\text { GSYIH Oranı }\end{array}$ & & $\begin{array}{c}\text { Devlet Harcamalar1 / } \\
\text { GSYIH Oran1 }\end{array}$ \\
\hline 2002 & 59.90 & 2010 & 27.37 \\
\hline 2003 & 53.58 & 2011 & 20.77 \\
\hline 2004 & 47.57 & 2012 & 15.32 \\
\hline 2005 & 40.10 & 2013 & 10.90 \\
\hline 2006 & 32.68 & 2014 & 9.14 \\
\hline 2007 & 28.16 & 2015 & 6.88 \\
\hline 2008 & 26.85 & 2016 & 8.40 \\
\hline 2009 & 30.92 & Ortalama & $\mathbf{2 7 . 9 0}$ \\
\hline
\end{tabular}

Kaynak: Hazine ve Maliye Bakanlığı

Görüldüğü üzere borç stokunun GSYİH'ya oran1 2002 ve 2005 yılları arasında \%40'1n üstünde seyretmektedir. Ancak ortalamada \%27.90 değerine ulaşmaktadır. Kova Yaklaşımında konjenktürel faktörler son adımda dikkate alındığı için bu istatistik yorumlanırken ortalama değer üzerinde durulacaktır. Bu sebeple Türkiye'ye borç stoku karakteristik puanı olarak 1 atanacaktır.

\subsubsection{Kamu Harcamaları / Gelirleri}

Nicoletta Batini, Luc Eyraud, ve Anke Weber (2014), Kamu harcama ve gelir yönetiminin etkinliğinin mali çarpanın değerini etkilediğini düşünmektedir. Vergilerin toplanmasındaki zorluklar ve harcama yetersizliklerinin maliye politikasının çıktı üzerindeki etkisini sınırlayabileceği bu sebeple de mali çarpanın düşük olacağı çalışmada vurgulanmaktadır. Ancak bu kriterin ölçümü için, araştırmacılar tarafindan net bir endeks oluşturmamış veya mevcut endeksler referans gösterilmemiştir. Çalışmada Amerika ekonomisi 
için yapılan örnekte ilgili kriter net bir veri setine dayanarak değil yorumlanarak analize dahil edilmiştir. Yapılan araştırma sonucunda ulusal veya uluslararası kuruluşlar tarafindan oluşturulan ve mali yönetimin etkinliğini ölçen bir veri seti / endeks bulmak mümkün olmamıştır. Benzer şekilde Milan Deskar-Škrbić ve Hrvoje Šimović tarafından (2015) Hırvatistan, Sırbistan ve Slovenya için Kova Yaklaşımı kullanılarak mali çarpanın hesaplandığı çalışmada, araştırmacılar bu kriteri ölçecek net bir ölçüt olmadığını savunarak kriter için bir puan ataması yapmamıştır. $\mathrm{Bu}$ araştırma da mali yönetimin etkinliği net bir endekse dayandırılamadığı için kriter için puan ataması yapılmaması uygun görülmüştür.

\subsection{Kova Yaklaşımının İkinci Adımı: Mali Çarpanın Belirlenmesi}

Kova yaklaşımının ikinci aşamasında, birinci yıl çarpanının "normal" zamanlardaki muhtemel seviyesini (düşük, orta veya yüksek) belirlemek için karakter özelliklerine atanan puanların toplanması istenmektedir. Nicoletta Batini, Luc Eyraud, ve Anke Weber (2014), çarpanın seviyesini belirleyen faktörlerin göreceli önemine dair sınırlı ampirik kanıt olduğu göz önünde bulundurarak, tüm yapısal özelliklere eşit ağırlık vermektedir. Toplama işlemi sonucunda 0-3 arasında puan alan ülkelerde mali çarpanın 0.1-0.3 arasında değer aldığ dolayısıyla düşük bir çarpanın olduğu düşünülmektedir. Eğer skor 3 veya 4 ise orta seviyede bir çarpan söz konusudur ve değeri 0.4-0.6 arasındadır. Yüksek seviyeli bir çarpan için ülkenin 4-6 arasında skor alması gerekmektedir. Bu durumda da çarpanın değeri 0.7-1 aralığında olacaktır. Kısaca, araştırmacılar tarafindan ülkeler karakteristik özelliklerinden aldıkları puanların toplamına göre kategorize edilerek, normal dönem çarpanının değeri için bir tahmin yapılmaktadır. Toplam puanları 3 veya 4 olan ülkeler birden fazla kategoride sonuçlanabilmektedir, araştırmacılar bu durumu ülkeye özgü yapısal özellikler ile ilgili yargılarda bulunmak için bir firsat olarak değerlendirmektedir. Araştırmada, her ülke grubuna bir puan değeri yerine çarpan aralığı tanımlanmıştır. Bunun sebebi, aynı gruptaki ülkeler arasındaki farklılıkları hesaba katmak ve çarpanları seçerken araştırmacılara yorumlama hakkı tanımaktır. Aşağıdaki çizelgede araştırmacıların alınan puanlara göre belirledikleri çarpan aralıkları yer almaktadır. 
Tablo 5. Çarpan Aralıkları

\begin{tabular}{|c|c|c|}
\hline Toplam Skor & Kategori & Çarpan Aralığ \\
\hline $0-3$ & Düşük & $0.1-0.3$ \\
\hline $3-4$ & Orta & $0.4-0.6$ \\
\hline $4-6$ & Yüksek & $0.7-1.0$ \\
\hline
\end{tabular}

Kaynak: Nicoletta Batini, Luc Eyraud, ve Anke Weber (2014)

Tablo 6. Türkiye'nin Karakteristik Puanı

\begin{tabular}{|c|c|}
\hline Kriter & Atanan Puan \\
\hline Ticaret Serbestliğinin Azlığ1 & 1 \\
\hline İşücü Piyasası Katılığı & 1 \\
\hline Otomatik Dengeleyicilerin Küçüklüğü & 1 \\
\hline Döviz Kuru Rejiminin Serbestliği & 0 \\
\hline Kamu Borç Stokunun Azlığı & 1 \\
\hline Kamu Harcamaları / Gelirleri & belirsiz \\
\hline Toplam & $\mathbf{4}$ \\
\hline
\end{tabular}

Bir önceki bölümde detaylandırılan analizler sonucunda, Türkiye ekonomisi ticaret serbestliğinin düşük olması, işgücü piyasasının katı olması, otomatik dengeleyicilerin küçük olması ve kamu borç stokunun az olması sebebiyle ilgili kriterlerden 1'er puan almıştır. Döviz kuru 2001 sonrasında serbest olduğu için 0 puan almıştır. Kamu harcamalarının ve gelirlerinin verimliliği kriteri literatürde diğer ülkeler için yapılan araştırmalarda olduğu gibi geçerli bir endeks tespit edilemediği için puanlamaya dahil edilmemiştir. Sonuç olarak Türkiye'nin karakteristik puanı 4 olarak hesaplanmıştır. Bu puan orta ve yüksek çarpanlı ülkelerin olduğu kategoilere dahildir. Kısaca Türkiye için Kova yöntemi ile hesaplanan normal dönem çarpan değeri, 0,4 ve 1 aralığındadır.

\subsection{Kova Yaklaşımının Üçüncü Adımı: Mali Çarpanın Ölçeklendirilmesi}

Kova yaklaşımının ilk aşamasında mali çarpanı etkileyeceği düşünülen karakteristik özellikleri üzerinde durulup bu özellikler analiz edilerek ülkelere puan atanmaktadır. İkinci aşamada bu puanlar toplanarak ülkeler düşük, orta ve yükssek çarpanların bulunduğu kategorilere ayrılmaktadır. Bu kategorilerde yer alan çarpanlar ülkelerin normal dönemlerdeki 
yani krizin ve yüksek büyümenin görülmediği, çıktı açığının sıfır olduğu dönemlerdeki çarpan tahmini olarak ifade edilmektedir. Üçüncü ve son aşamada ise güncel literatürde de siklıkla vurgulandığ1 üzere ekonominin içinde bulunduğu konjenktürel durum mali çarpan hesabına dahil edilmekte bu sayede ülke özelinde inceleme yapılması sağlanmaktadır.

Son dönemlerde yapılan araştırmalar maliye politikasının daralma dönemlerinde genişleme dönemlerine göre daha yüksek olduğu tespit edilmiştir. (Auerbach, ve Gorodnichenko, 2012) Araştırmacılar bu bulgulara kova yaklaşımında yer vererek ekonominin içinde bulunduğu iş döngüsünü birinci ölçeklendirme faktörü olarak metodolojiye eklemiştir. Ekonomide durgunluk söz konusu ise çarpan için tahmin edilen alt ve üst sınırların \%60 oranında arttırılması, ekonomide hızlı bir büyüme söz konusu ise çarpan için tahmin edilen alt ve üst sınırların \%40 oranında azaltılması gerektiği öngörülmüştür.

İkinci ölçeklendirme faktörü ise para politikasının durumudur. Genişleyen para politikası ve faiz oranlarının düşürülmesi, mali daralmanın talep üzerindeki etkisini hafifletebilmektedir. Buna karşılık, para politikasının kullanımı ve/veya aktarımının bozulmasına (nominal faizin sıfır alt sınırında olması gibi) bağlı olarak, çarpanlar potansiyel olarak daha büyük olabilir. Diğer bir ifadeyle, para politikası iletim mekanizmaları aracılığıyla veya nominal faizin sıfır alt sınırında olması sebebiyle kısıtlanmışsa maliye politikasının etkinliği (mali çarpan) daha yüksektir. (Erceg ve Lindé, 2010) Araştırmacılar, para politikası etkin bir alt sınırdaysa ve tamamen kısıtlıysa, çarpan aralığının her iki sınırını da \%30 arttırılması gerektiğini belirtmektedir. Para politikası diğer hususlarla sınırlandırılmışsa, \%0$\% 30$ aralığında bir enterpolasyon önerilmektedir.

Aşağıdaki formülde normal dönem çarpanının ölçeklendirilmesi anlatılmaktadır. " $\mathrm{M}_{\mathrm{nt}}$ " kova yaklaşımının ikinci aşamasında hesaplanan normal zamanlarda gözlemlenen mali çarpanı ifade etmektedir. "Cycle" ise -0.40 ile 0.60 arasında değer alan iş döngüsü faktörünü; "Mon" ise para politikası duruşunu göstermekte ve 0 ile 0.30 arasında değer alabilmektedir.

$$
\mathrm{M}=\mathrm{M}_{\mathrm{nt}} *(1+\mathrm{Cycle}) *\left(1+\mathrm{M}_{\mathrm{on}}\right)
$$

$\mathrm{Bu}$ aşamada öncelikle Türkiye ekonomisinin 2002-2016 yılları arasındaki iş döngüsü incelenmelidir. H. Murat Özbilgin'in (2017) çalışmasında Türkiye'nin 1999 - 2016 yılları arasındaki iş döngüsü grafiği oluşturmuştur. 
Şekil 1. Türkiye İçin İş Döngüleri

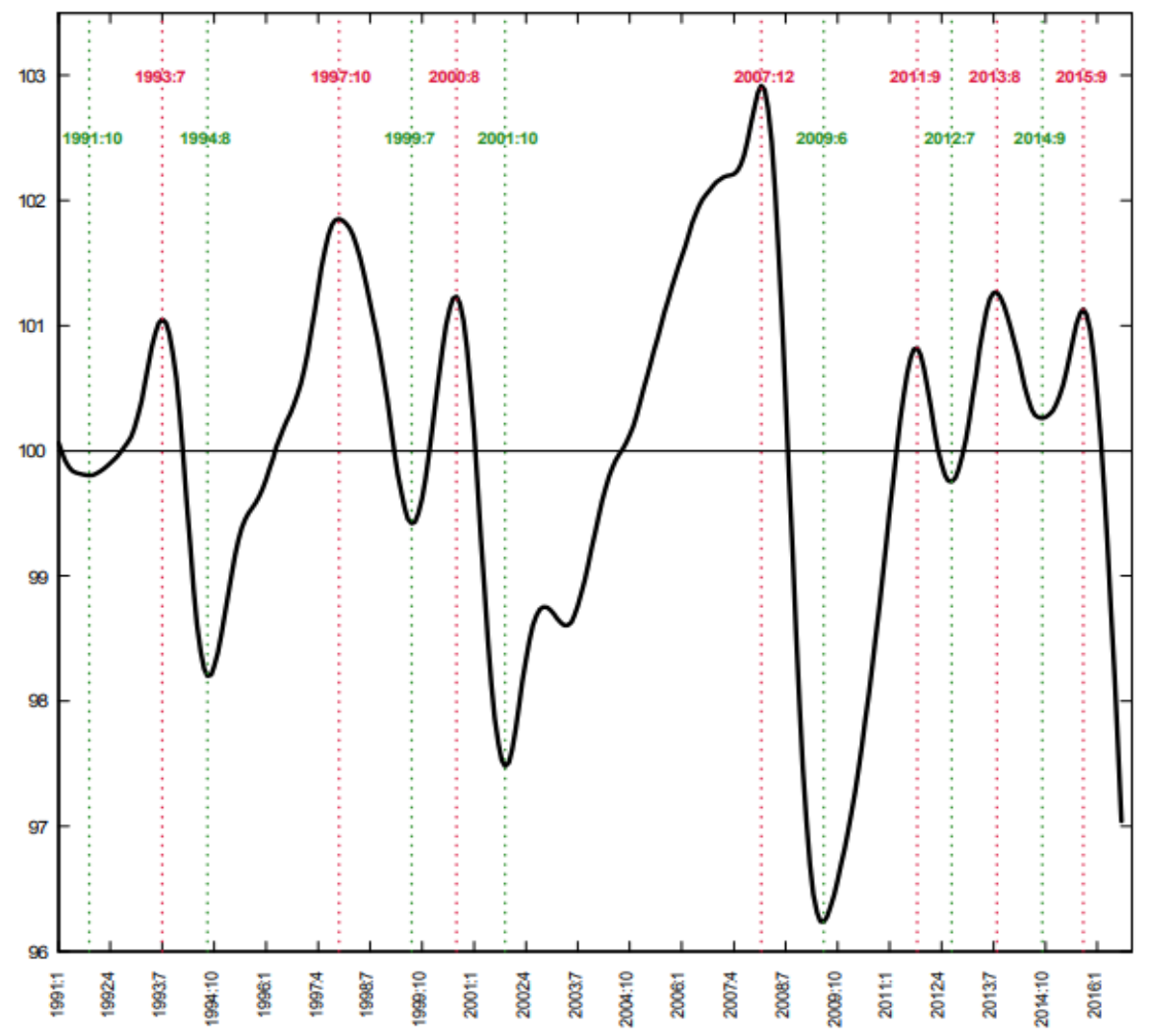

Kaynak: H. Murat Özbilgin (2017)

Yukarıda yer alan şekil incelendiğinde, 2009 ve 2016 yıllarında negatif çıktı açığının dip noktada olduğu, 2007 yılında ise pozitif çıktı açığının verilen tarih aralığındaki en yüksek değere ulaştığı gözlenmektedir. 2004 ve 2012 yıllarında ise negatif veya pozitif çıktı açığı görülmemektedir. Bu kapsamda Türkiye için 2009 ve 2016 yılları için \%60 arttırılması, 2007 yılındaki çarpanın \%40 azaltılması ve 2004 ile 2012 yılları için ise herhangi bir ölçeklendirilme yapılmaması uygun görülmüştür. Diğer yıllar için ise maksimum ve minimum noktalara olan uzaklıklara göre yaklaşık bir ölçek değeri atanmıştır. Örneğin 2003 yılındaki iş döngüsü, negatif çıktı açığını göstermekle birlikte, aralıktaki en düşük değerin yarısı civarındadır. $\mathrm{Bu}$ sebeple 2003 yılındaki ölçek maksimum değer olan \%60'ın yarısı olacak şekilde \%30 olarak atanmıştır. Aşağıdaki tabloda yıl bazında atanan iş döngüsü ölçeği değerleri gösterilmektedir. 
Tablo 7. İş Döngüsü Dikkate Alınarak Atanan Ölçek Değeri

\begin{tabular}{|c|c|}
\hline & $\begin{array}{c}\text { İş Döngüsü Dikkate Alınarak Atanan Ölçek } \\
\text { Değeri } \\
(\mathbf{- 0 . 4 - 0 . 6 )}\end{array}$ \\
\hline 2002 & 0.4 \\
\hline 2003 & 0.3 \\
\hline 2004 & 0 \\
\hline 2005 & -0.1 \\
\hline 2006 & -0.2 \\
\hline 2007 & -0.4 \\
\hline 2008 & 0.4 \\
\hline 2009 & 0.6 \\
\hline 2010 & 0.4 \\
\hline 2011 & -0.1 \\
\hline 2012 & 0 \\
\hline 2013 & -0.2 \\
\hline 2014 & -0.1 \\
\hline 2015 & -0.2 \\
\hline 2016 & 0.6 \\
\hline
\end{tabular}

Batini, Eyraud ve Weber'e göre ülkenin konjentürel durumu göz önünde bulundurulurken dikkate alınacak ikinci ölçeklendirme faktörü para politikasının duruşudur. Daha önce ifade edildiği üzere eğer para politikası nominal faizin sıfır alt sınırında olması sebebiyle kısıtlanmışsa maliye politikasının etkinliği (mali çarpan) daha yüksektir. Bu durumu ölçmek için Merkez Bankası gecelik borç alma ve verme faizinin oluşturduğu faiz koridorunda nominal faiz oranının denk geldiği sınırlara dikkat etmek gerekecektir. Eğer nominal faiz alt sınırlara yakın ise para politikasının kısıtlandığı yorumunda bulunulabilir. Merkez bankasından alınan veriler ile 2002-2016 yılları arasında gecelik borç alma ve verme faizinin ve nominal net faizin grafikleri aşağıdaki gibi oluşturulmuştur. 
Şekil 2. Türkiye İçin Faiz Koridoru ve Nominal Faiz Oranı

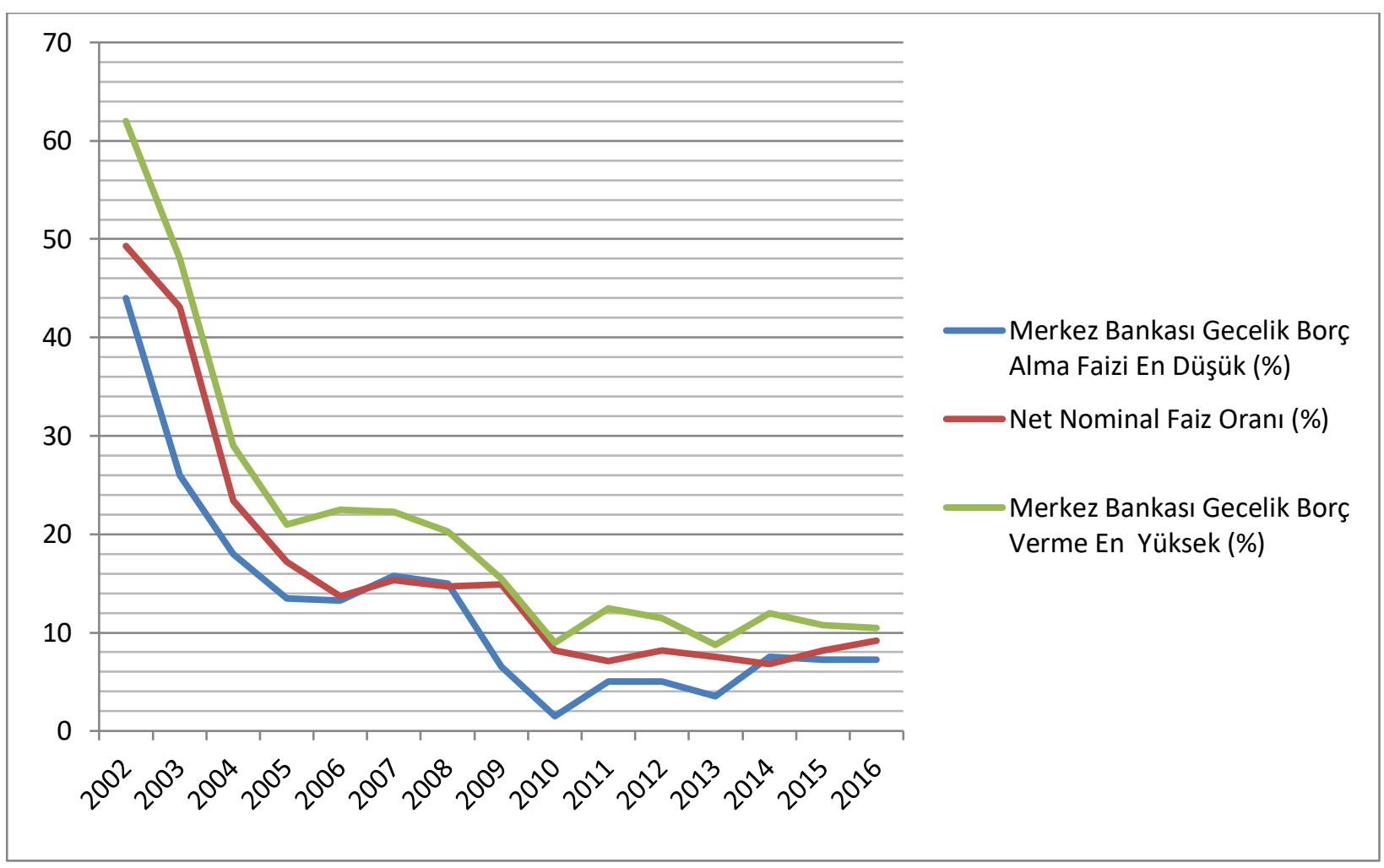

Kaynak: Merkez Bankas1

Görüleceği üzere 2006, 2007, 2008, 2014 ve 2015 y1llarında net nominal faiz, gecelik borç alma faizinin en düşük seviyesine yakın seyretmektedir. Bu sebeple ilgili yıllar için para politikasının kısıtlı olduğu yorumu yapılabilir. Dolayısıyla, bu yıllar için \%30 ölçek atanması uygun görülmüştür. Net nominal faiz oranının borç verme üst sınırına yakın olduğu 2009, 2010, 2013 ve 2016 yılları için ise \%10 ölçek atanacaktır. Net nominal faiz oranının faiz koridorunun ortasında seyrettiği yıllarda ölçeklendirme yapılmaması uygun görülmüştür. Aşağıdaki tabloda yıllara göre atanan para politikası çarpan değerlerine yer verilmektedir. 
Tablo 8. Para Politikası Duruşu İçin Atanacak Ölçek Değerleri

\begin{tabular}{|c|c|}
\hline & $\begin{array}{c}\text { Para Politikası Duruşu için Atanacak } \\
\text { Ölçek Degerleri } \\
(-0.4-0.6)\end{array}$ \\
\hline 2002 & 0 \\
\hline 2003 & 0 \\
\hline 2004 & 0 \\
\hline 2005 & 0 \\
\hline 2006 & 0.3 \\
\hline 2007 & 0.3 \\
\hline 2008 & 0.3 \\
\hline 2009 & 0.1 \\
\hline 2010 & 0.1 \\
\hline 2011 & 0 \\
\hline 2012 & 0 \\
\hline 2013 & 0.1 \\
\hline 2014 & 0.3 \\
\hline 2015 & 0.3 \\
\hline 2016 & 0.1 \\
\hline
\end{tabular}

Son olarak atanan konjenktürel değerler dikkate alınarak normal dönem çarpan aralığının üst ve alt sınırlarının aşağıdaki formüle uygun olarak güncellenmesi gerekmektedir.

$$
\mathrm{M}=\mathrm{M}_{\mathrm{nt}} *(1+\mathrm{Cycle}) *\left(1+\mathrm{M}_{\mathrm{on}}\right)
$$

Aşağıdaki Tabloda bu işlem sonrasında ulaşılan yeni çarpan aralığı gösterilmektedir. Bu aralıklar ilgili yılın ekonomik koşulları dikkate alınarak oluşturulmuştur. Tabloda görüleceği üzere Türkiye ekonomisinde işlerin yolunda olmadığı 2002, 2003, 2006, 2008, 2009, 2010, 2014, 2015 ve 2016 yıllarında mali çarpan değeri 1'in üzerine doğru hareketlenmektedir. Normal dönemler olarak adlandırılabilecek olan diğer yıllarda mali çarpanın üst sınırı 1 sınırında görülmektedir. Sonuçlar genel literatürdeki beklentilerle uyumlu olup, detaylı olarak aşağıdaki bölümünde analiz edilmiştir. 
Tablo 9. Ölçeklendirme Sonrası Y1llara Göre Mali Çarpan Aralığı

\begin{tabular}{|c|c|c|c|c|c|}
\hline & $\begin{array}{c}\text { Normal } \\
\text { Dönem Mali } \\
\text { Çarpan } \\
\text { Aralığı }\end{array}$ & $\begin{array}{c}\text { İş Döngüsü } \\
\text { Dikkate Alınarak } \\
\text { Atanan Ölçek } \\
\text { Değeri } \\
(-0.4-0.6)\end{array}$ & $\begin{array}{c}\text { Para Politikası } \\
\text { Duruşu için } \\
\text { Atanacak Ölçek } \\
\text { Değerleri } \\
(-0.4-0.6)\end{array}$ & $\begin{array}{c}\text { Ölçekleme } \\
\text { Sonrası Mali } \\
\text { Çarpan Alt } \\
\text { Sınırı }\end{array}$ & $\begin{array}{c}\text { Ölçekleme } \\
\text { Sonrası Mali } \\
\text { Çarpan Üst } \\
\text { Sınırı }\end{array}$ \\
\hline 2002 & $0.4-0.1$ & 0.4 & 0 & 0.56 & 1.4 \\
\hline 2003 & $0.4-0.1$ & 0.3 & 0 & 0.52 & 1.3 \\
\hline 2004 & $0.4-0.1$ & 0 & 0 & 0.40 & 1 \\
\hline 2005 & $0.4-0.1$ & -0.1 & 0 & 0.36 & 0.9 \\
\hline 2006 & $0.4-0.1$ & -0.2 & 0.3 & 0.42 & 1.04 \\
\hline 2007 & $0.4-0.1$ & -0.4 & 0.3 & 0.31 & 0.78 \\
\hline 2008 & $0.4-0.1$ & 0.4 & 0.3 & 0.73 & 1.82 \\
\hline 2009 & $0.4-0.1$ & 0.6 & 0.1 & 0.70 & 1.76 \\
\hline 2010 & $0.4-0.1$ & 0.4 & 0.1 & 0.62 & 1.54 \\
\hline 2011 & $0.4-0.1$ & -0.1 & 0 & 0.36 & 0.9 \\
\hline 2012 & $0.4-0.1$ & 0 & 0 & 0.40 & 1 \\
\hline 2013 & $0.4-0.1$ & -0.2 & 0.1 & 0.35 & 0.88 \\
\hline 2014 & $0.4-0.1$ & -0.1 & 0.3 & 0.47 & 1.17 \\
\hline 2015 & $0.4-0.1$ & -0.2 & 0.3 & 0.42 & 1.04 \\
\hline 2016 & $0.4-0.1$ & 0.6 & 0.1 & 0.70 & 1.76 \\
\hline
\end{tabular}

\section{Sonuç}

Türkiye hem orta hem de yükssek çarpan aralığına girdiği için hesaplanan mali çarpan aralığ oldukça geniştir. Bununla birlikte bazı yıllarda çarpan aralığı ekonominin içinde bulunduğu konjenktürü yansıtacak şekilde genişlemektedir. 2001 krizi etkilerinin görüldüğü 2002 yılında çarpan değeri 1.4'e kadar artmıştır. 2003 yılında benzer şekilde ufak düşüklerle birlikte krizin etkisi devam ederek aralık 0.52 ile 1.3 olarak ölçülmüştür. Krizin etkisini yitirmeye başladığ 1 2005 ve 2006 yıllarında çarpanın da etkisi azalmaktadır. Bu dönemde değer 0.3 ile 0.9 aralığına gerilemektedir. Türkiye'nin zımni enflasyon hedeflemesinden açık enflasyon hedeflemesine geçtiği 2006 yılında Asya krizinin etkisiyle görülen ithal enflasyon para politikası üzerinde baskı oluşturmuş ve son beş yıl içerisinde ilk kez para politikasının sınırlandığı görülmüştür. $\mathrm{Bu}$ durum mali çarpan değerinde bir yükseliş trendi oluşturmuştur. Bununla birlikte büyük bir sıçrama olduğunu söylemek mümkün değildir. Türkiye'nin 15 yıllık aralıkta iş döngüsünün en yüksek seviyeye çıktığg 2007 yılında çarpan değeri en düşük aralığa ulaşmaktadır. Ekonominin 
iyi gittiği dönemlerde dışlama etkisi nedeniyle çarpanın düşük çıkacağı görüşü Türkiye ekonomisi için de sağlanmış görünmektedir. 2008 yılında ise tüm dünyayı sarsan morgage krizinin etkileri sert bir şekilde çarpan değerini değiştirmiştir. Mali çarpanın üst ve alt sınırlarında ciddi bir sıçrayış ölçülmektedir. Bu yıl çarpan aralığı 0.8 ve 1.82 arasında ölçülerek 15 yıllık projeksiyonun en yüksek seviyesine ulaşmıştır. Bu bulgu çalışmanın ilk kısımlarında özetlenen güncel akademik literatürün öngördüğü şekilde kriz dönemlerinde mali çarpanının normal dönemlere oranla çok daha yüksek olduğunu ve dışlama etkisinin azaldığını kanıtlar şekildedir. 2009 ve 2010 yıllarında kriz etkisini azaltmakla birlikte hala çarpan yüksek seviyelerde seyretmektedir. Normalleşme süreci olarak adlandırılabilecek olan 2011 - 2013 döneminde mali çarpan, 2004 ve 2005 yıllarındaki düzeylere gerilemektedir. 2014 yılına gelindiğinde Merkez Bankasının enflasyonu dizginlemek amacıyla likiditeyi azaltmaya yönelik yaptığı hamleler ve doğrudan yabancı yatırımlardaki azalış para politikasının kısıtlanması ile sonuçlanmış ve mali çarpan değeri tekrar yükselmiştir. 2015 yılında küçük bir toparlanma yaşanmış olsa da 2016 yılında negatif çıktı açığg 2009 olduğu gibi en alt noktaya doğru hareketlenmiş ve derinleşen krizin etkisi mali çarpanın büyüklüğüne yansımıştır.

Bulunan sonuçlar, güncel uluslararası literatüründeki araştırmaların sonuçları ile benzerlik taşımaktadır. Kriz dönemlerinde mali çarpanın etkisi artmakta, normal dönemlerde ise dışlama etkisinin varlığı ortaya çıkarak çarpan değeri azalmaktadır. Bununla Türkiye'nin karakteristik özelliklerine atanan puanlar nedeniyle orta ve yüksek olmak üzere iki ayrı kategoride yer alması çarpan aralığının geniş ölçülmesi ile sonuçlanmaktadır. Bu durum Nicoletta Batini, Luc Eyraud, ve Anke Weber'in (2014) belirttiği üzere yorumlamaya açık bir pencere birakmaktadır. Cem ÇEBİ tarafından (2017) yapılan çalışmada Türkiye ekonomisindeki mali çarpanın değeri 20022014 yıllarını kapsayan veri setiyle Yapısal Vektör Otoregresif Modeli kullanılarak tahmin edilmiştir. Bu çalışmanın sonuçları, büyük ölçüde mevcut uluslararası literatürün bulgularıyla paraleldir. Çalışmada mali çarpanın ikinci çeyrekte en büyük değerini alarak, 1,5 değerine ulaştığ 1 belirtilmiş, bir yıllık birikimli çarpan 0,9 olarak hesaplanmıştır. Çizelgede bulunan çarpan değerleri dikkate alındığında bulunan aralıkların normal dönemlerde 0.9'u, yoğun kriz dönemlerinde ise 1.5 değerini içerdiği görülmektedir. Bununla birlikte ülke puanının yüksek kategoride yer alınmasından dolayı üst limitler 1.5 bandının daha da üstünde yer almaktadır. Burada Nicoletta Batini, Luc Eyraud, ve Anke Weber'in (2014) dile getirdiği ülkeler özelinde yorumlama ihtiyacı doğmaktadır. Türkiye'nin gelişmekte olan bir ekonomi olmasına rağmen dünyanın önde gelen ilk 20 ekonomisi içinde yer alıyor olması ülkeye özel bir konum 
kazandırmaktadır. Bu sebeple orta ve yüksek çarpan kategorilerinden herhangi birini tercih etmek doğru olmayacaktır. Her iki kategorinin de özellikleri Türkiye ekonomisinde görülmektedir. Bununla birlikte orta ve yüksek çarpan kategorilerine atanan 0.4 ile 1 aralığ özelinde Türkiye için ayrı bir yorumlama yapılabilir. Bu aralık, Türkiye'ye özel olarak 0.6 ile 0.8 bandına çekilebilir. Bu durumda ortalama çarpan $0.8^{\prime}$ lerda seyredecek, maksimum $1.45^{\prime} \mathrm{e}$ kadar yükselecektir. Böylelikle sonuçlar Türkiye ekonomisi ile ilgili diğer araştırmaların sonuçları ile daha iyi uyum sağlayacaktır.

\section{Kaynakça}

Auerbach, A. J. ve Gorodnichenko, Y. (2012). "Measuring the Output Responses to Fiscal Policy". American Economic Journal, 4 (2), 1-27.

Barrell, R., Holland D., ve Hurst I. (2012) "Fiscal Consolidation: Part 2. Fiscal Multipliers and Fiscal Consolidations”. OECD Economics Department Working Paper, 933

Barro, R. (1989). "The Neoclassical Approach to Fiscal Policy. Modern Business Cycle Theory". Harvard University Press, 178-235.

Batini, N., Eyraud L. ve Weber, A. (2014). “A Simple Method To Compute Fiscal Multipliers”. IMF Working Paper, 14 (93).

Baum, A., Poplawski-Ribeiro, M., ve Weber, A., (2012). "Fiscal Multipliers and the State of the Economy". IMF Working Paper, 12 (286).

Blanchard, O. ve Leigh, D. (2013). "Growth Forecast Errors and Fiscal Multipliers". IMF Working Paper, 13 (1), 2-5.

Born, B., Juessen, F., ve Mueller, G .J., (2013). "Exchange rate regimes and fiscal multipliers," Journal of Economic Dynamics and Control, 37 (2), 446-65.

Cole, H.L., ve Ohanian L.E., (2004). "New Deal Policies and the Persistence of the Great Depression: A General Equilibrium Analysis," Journal of Political Economy, 112 (4), 779-816.

Corsetti, G.,Meier, A., ve Muller, G. (2012). "What Determines Government Spending Multipliers". Economic Policy, 27 (72), 521-565.

Çebi, C., (2017). "The Government SpendingMultiplier in Turkey", Journal of Emerging Markets Finance and Trade, 53.

Deskar Škrbić, M., ve Šimović, H., (2015). "The size and determinants of fiscal multipliers in Western Balkans: comparing Croatia, Slovenia and Serbia", EFZG Working Paper Series, (10), 1-21.

Dolls, M., Fuest, C., ve Peichl A., (2012). "Automatic Stabilizers and Economic Crisis: US vs. Europe,” Journal of Public Economics,96, 279-94. 
Erceg, C. J., ve Lindé, J., (2010). "Is There a Free Lunch in a Liquidity Trap?" International Finance Discussion Papers ,1003.

Ganelli G. ve Tervala J., (2016). "The Welfare Multiplier of Public Infrastructure Investment." IMF Working Papers, 16(40).

Hall R.E., (2009). "By How Much Does GDP Rise If the Government Buys More Output?", Brookings Papers on Economic Activity, 40(2), 183-185.

Hernández de Cos, P. ve Moral-Benito, E., (2013). "Fiscal Multipliers in Turbulent Times: The Case of Spain". Banco de Espana Working Paper, (1309).

Ilzetzki, E., Mendoza, E.G. ve Vegh C.A. (2013). "How Big (Small?) Are Fiscal Multipliers?". IMF Working Paper, 11(52), 26-27.

Keynes, M. J. (1936). The General Theory Of Employment, Interest and Money. London: Macmillan.

Kirchner, M., Cimadomo, J. ve Hauptmeier, S., (2010), "Transmission of Government Spending Shocks in The Euro Area: Time Variation and Driving Forces," ECB Working Paper Series, 1219

McDonough, T. (2008). "Social Structures of Accumulation Theory: The State of the Art." Review of Radical Political Economics, 40.

Perotti, R., (2004). "Estimating the Effects of Fiscal Policy in OECD Countries". IGIER Working Paper, 276.

Özgün, H. M., (2017). "Forecasting the Growth Cycles of the Turkish Economy" TCMB Working Papers, 17 (15)

https://evds2.tcmb.gov.tr/

https://www.hmb.gov.tr/kamu-finansmani-istatistikleri

http://tuik.gov.tr/Start.do

https://data. worldbank.org/country/turkey?locale=tr 